\title{
Stimulatory Effects of Stress on Gonadotropin Secretion in Estrogen-Treated Women*
}

\author{
JARDENA J. PUDER, PAMELA U. FREDA, ROBIN S. GOLAND, MICHEL FERIN, \\ AND SHARON L. WARDLAW \\ Departments of Medicine (J.J.P., P.U.F., R.S.G., S.L.W.) and Obstetrics and Gynecology (M.F.), \\ Columbia University College of Physicians and Surgeons, New York, New York 10032
}

\begin{abstract}
Although stress is known to inhibit the hypothalamic-pituitarygonadal axis, recent studies in the monkey show that, under certain conditions, in the presence of estrogen, stress may actually stimulate $\mathrm{LH}$ release. We investigated the effects of a mild inflammatory stress $(2.0-3.0 \mathrm{ng} / \mathrm{kg}$ endotoxin) on $\mathrm{LH}$ release in five postmenopausal women with and without transdermal estradiol (E2, $0.1 \mathrm{mg})$ replacement. In another five E2-treated women, LH release was studied when the adrenal was stimulated directly by a 3-h ACTH infusion (Cortrosyn, $50 \mu \mathrm{g} / \mathrm{h}$ ). Mean E2 levels were less than $12 \mathrm{pg} / \mathrm{mL}$ in the unreplaced subjects and were $86 \pm 10 \mathrm{pg} / \mathrm{mL}$ and $102 \pm 18 \mathrm{pg} / \mathrm{mL}$ in the two groups of E2-replaced subjects. Blood was sampled every 15-20 min for $2 \mathrm{~h}$ before and for $7 \mathrm{~h}$ after endotoxin or ACTH injection. Mean cortisol and progesterone levels increased in all three groups over time $(P<0.001)$. In the women without $\mathrm{E} 2$ replacement, basal $\mathrm{LH}$ was $26.8 \pm 5.3 \mathrm{mIU} / \mathrm{mL}$ and did not change significantly, over
\end{abstract}

time, after endotoxin $(P=0.58)$. In the same women on $\mathrm{E} 2$, however, a significant increase in LH occurred after endotoxin $(P=0.02)$, from a mean hourly baseline of $15.3 \pm 5.4 \mathrm{mIU} / \mathrm{mL}$ to a peak of $50.0 \pm 25.2$ $\mathrm{mIU} / \mathrm{mL}$. During the ACTH infusion, there was a significant stimulation of LH release in the E2-replaced subjects $(P<0.001)$, from a mean hourly baseline of $13.3 \pm 3.0 \mathrm{mIU} / \mathrm{mL}$ to a peak of $44.1 \pm 11.7$ $\mathrm{mIU} / \mathrm{mL}$. In both groups, this increase occurred $2-4 \mathrm{~h}$ after the initial rise in progesterone and persisted to the end. We conclude that, in the presence of sufficient estrogen, activation of the hypothalamic-pituitary-adrenal axis leads to a stimulation of $\mathrm{LH}$ release. This is likely related to a rise in adrenal progesterone and its known stimulatory effect on LH release in the presence of E2. These studies provide a potential mechanism in the human by which an acute stress during the follicular phase of the menstrual cycle might lead to a premature LH surge and thereby interfere with follicular maturation and ovulation. (J Clin Endocrinol Metab 85: 2184-2188, 2000)
$S^{T}$ RESS IS KNOWN to interfere with the menstrual cycle and may lead to chronic anovulation and amenorrhea $(1,2)$. This is generally thought to be caused by a decrease in the activity of the hypothalamic $\mathrm{GnRH}$ pulse generator with subsequent inhibition of the pituitary-gonadal axis (3-5). There is considerable evidence that stress-induced activation of the hypothalamic-pituitary-adrenal (HPA) axis plays an important role in suppressing the hypothalamic-pituitarygonadal (HPG) axis (6). In animals, CRH has been shown to suppress the GnRH pulse generator, resulting in a decrease in pulsatile $\mathrm{LH}$ release $(7,8)$. CRH antagonism has also been shown to prevent the inhibitory effect of stress on the HPG axis in the rodent and in the monkey $(3,9)$. Women with hypothalamic amenorrhea have higher basal cortisol levels and a blunted cortisol response to exogenous administration of $\mathrm{CRH}$, suggesting that the increase in cortisol secretion may reflect increased endogenous CRH activity (10). These women with functional hypothalamic amenorrhea also show significant slowing of their LH pulse frequency (11).

Recent data in the monkey, however, demonstrate that the effect of stress on LH release depends on the stage of the

Received October 13, 1999. Revision received February 24, 2000. Accepted February 27, 2000.

Address correspondence and requests for reprints to: Dr. Sharon L. Wardlaw, Department of Medicine, Columbia University College of Physicians and Surgeons, 630 West 168th Street, New York, New York 10032. E-mail: sw22@columbia.edu.

* This work was supported by NIH Grants R01-MH55708 and RR00645 (to the Columbia General Clinical Research Center). Presented in part at the 81st Annual Meeting of The Endocrine Society, San Diego, California, 1999 (Abstract P2-56). menstrual cycle and the level of circulating estradiol (E2). In ovariectomized monkeys without E2 replacement, inflammatory stress, induced by intracerebroventricular (ICV) injection of the cytokine interleukin- $1 \alpha$ (IL- $1 \alpha)$, suppressed LH by a CRH-dependent mechanism (9). However, in estrogenreplaced ovariectomized monkeys and in intact monkeys during the midfollicular phase of the menstrual cycle, administration of IL- $1 \alpha$ actually stimulated LH-secretion (12, 13). The IL- $1 \alpha$-induced stimulation of adrenal cortisol release was accompanied by a parallel increase in progesterone levels. It was postulated that the rise in plasma progesterone, of adrenal origin, which occurs in response to HPA activation, synergizes with circulating E2 to enhance LH secretion (5). This was further supported by the finding that the progesterone antagonist RU486 prevented the IL- $1 \alpha$-induced increase in LH in the monkey (12).

It is not known whether estrogen can similarly affect the $\mathrm{LH}$ response to stress in humans. We therefore studied the effects of a mild inflammatory stress, in the form of endotoxin, on LH release in postmenopausal women with and without estrogen replacement. We also investigated the LH response in estrogen-treated postmenopausal women when the adrenal was activated directly by an ACTH infusion.

\section{Subjects and Methods}

\section{Experimental protocol}

Endotoxin study. Five healthy female subjects, 51-68 yr old, were studied. Three subjects were at least 1 yr after natural menopause, and two had undergone a bilateral oophorectomy 3-4 yr before. Subjects received low-dose endotoxin on 
two occasions separated by 1-2 months. Subjects were studied in random order, either without estrogen replacement or with estrogen, which was administered for 1 month before the study, via a transdermal E2 patch $(0.1 \mathrm{mg})$. Mean ( \pm SEM) E2 levels were $6.4 \pm 0.9 \mathrm{pg} / \mathrm{mL}$ before the study in the unreplaced subjects and $86 \pm 10 \mathrm{pg} / \mathrm{mL}$ after E2. Unreplaced subjects were documented to have low E2 levels for at least 2 months before receiving endotoxin.

An indwelling iv catheter was inserted at $0800 \mathrm{~h}$ on the day of the study. Purified endotoxin was given iv at $1000 \mathrm{~h}$, and blood was sampled every $20 \mathrm{~min}$ for $2 \mathrm{~h}$ before and for $7 \mathrm{~h}$ after endotoxin injection. All women experienced mild myalgias, occasional nausea, chills, and an increase in mean peak temperature, to $38.2 \mathrm{C}$ vs. $38.3 \mathrm{C}$, with and without E2, respectively. Two endotoxin preparations were used. The first four subjects received endotoxin (purified lipopolysaccharide prepared from Escherichia coli, US Pharmacopeia Endotoxin Reference Standard, EC-5), obtained from the US Pharmacopoeia (Bethesda, MD). The first woman received $3 \mathrm{ng} / \mathrm{kg}$, whereas the subsequent three subjects received 2.5 $\mathrm{ng} / \mathrm{kg}$. Because the EC-5 preparation became unavailable, the fifth patient received a more recently purified endotoxin preparation (US Standard Reference Endotoxin, PDS no. 67801), obtained from the Pharmaceutical Development Section, NIH (Bethesda, MD). This patient received $2 \mathrm{ng} / \mathrm{kg}$, because the latter endotoxin preparation was more potent. Each person received the same dose and preparation of endotoxin in both parts of the study.

ACTH study. Five healthy postmenopausal women, 36-59 yr old, were studied. None of these women had previously participated in the first study. Four subjects were at least 1 yr after natural menopause, and one had undergone a bilateral oophorectomy 1 yr before. Each subject was treated with a transdermal E2 patch $(0.1 \mathrm{mg})$ for 1 month. E2 levels were measured 4 days before the study and, if less than 50 $\mathrm{pg} / \mathrm{mL}$, an additional E2 patch was added. On the day of the study, mean E2 levels were $102 \pm 18 \mathrm{pg} / \mathrm{mL}$. Cortrosyn (ACTH 1-24, manufactured by Organon Inc., West Orange, NJ) was administered as a $50-\mu \mathrm{g}$ iv bolus at $1000 \mathrm{~h}$, followed by a 3-h infusion of $50 \mu \mathrm{g} / \mathrm{h}$. Blood was collected at 15-min intervals for $2 \mathrm{~h}$ before and $7 \mathrm{~h}$ after the initial bolus. In both studies, blood samples were centrifuged within $1 \mathrm{~h}$, and serum was stored at $-20 \mathrm{C}$ until assay.

Informed consent was obtained from all subjects, and both studies were approved by the Columbia-Presbyterian Medical Center Institutional Review Board.

\section{Assays}

Serum cortisol was assayed in unextracted plasma by solid-phase RIA (Diagnostic Products Corp., Los Angeles, CA). Progesterone and LH were measured by a commercial solid-phase, chemiluminescent immunoassay (Immulite; Diagnostic Products Corp.). The polyclonal antibodies used are highly specific for each hormone, with an assay sensitivity of $0.2 \mathrm{ng} / \mathrm{mL}$ for progesterone and $0.7 \mathrm{mIU} / \mathrm{mL}$ for $\mathrm{LH}$, respectively. Two assays were used for E2 measurements: All samples were measured by a commercial solid-phase, chemiluminescent immunoassay (Immulite; Diagnostic Products Corp.) with an assay sensitivity of $20 \mathrm{pg} / \mathrm{mL}$. In samples with E2 levels of less than $20 \mathrm{pg} / \mathrm{mL}$, the measurement was repeated using a sensitive double-antibody RIA for E2 (Diagnostic Products Corp.). Sensitivity of this assay was $5 \mathrm{pg} / \mathrm{mL}$.

E2 levels were measured twice at the start of each study, before endotoxin or $\mathrm{ACTH}$ injection, whereas cortisol and progesterone were measured at hourly intervals, and LH levels were measured on all samples obtained at 15 - to 20 -min intervals.

\section{Data analysis}

Mean LH levels per hour were calculated for each individual. For each subject, hourly changes were calculated as a percentage of the 2-h baseline. Mean ( \pm SEM) hourly LH, progesterone, and cortisol concentrations were calculated for each group. The area under the LH concentration curve was calculated by trapezoid analysis. Changes in hormone concentrations over time were analyzed by ANOVA with repeated measures. Statistical significance was set at $P<0.05$.

\section{Results}

\section{Endotoxin study}

Mean ( \pm SEM) basal cortisol and progesterone concentrations were $8.1 \pm 0.7 \mu \mathrm{g} / \mathrm{dL}$ and $0.3 \pm 0.03 \mathrm{ng} / \mathrm{mL}$ without E2 treatment and $9.0 \pm 0.9 \mu \mathrm{g} / \mathrm{dL}$ and $0.3 \pm 0.1 \mathrm{ng} / \mathrm{mL}$ with E2, respectively. Mean cortisol and progesterone levels rose significantly over time, from their $2 \mathrm{~h}$ baseline $(P<0.001$ in both groups), and peaked $4-5 \mathrm{~h}$ after endotoxin injection in both the unreplaced group $(31.7 \pm 3.6 \mu \mathrm{g} / \mathrm{dL}$ and $1.7 \pm 0.3$ $\mathrm{ng} / \mathrm{mL})$ and in the group on E2 $(30.5 \pm 3.3 \mu \mathrm{g} / \mathrm{dL}$ and $1.5 \pm$ $0.4 \mathrm{ng} / \mathrm{mL}$ ) (Figs. $1 \mathrm{~B}$ and $2 \mathrm{~B}$ ). In the women without E2 replacement, basal $\mathrm{LH}$ was $26.8 \pm 5.3 \mathrm{mIU} / \mathrm{mL}$ and did not change significantly over time $(P=0.58)$ (Fig. 1A). In the E2-replaced group, however, there was a significant stimulation of $\mathrm{LH}$ release $(P=0.02)$, which occurred $3-4 \mathrm{~h}$ after the initial rise in progesterone. Mean hourly LH increased from a baseline of $15.3 \pm 5.4 \mathrm{mIU} / \mathrm{mL}$ and peaked at $50.0 \pm$ $25.2 \mathrm{mIU} / \mathrm{mL}$ (Fig. 2A). In one individual, $\mathrm{LH}$ increased markedly, to a maximum of $185 \mathrm{mIU} / \mathrm{mL}$. The peak $\mathrm{LH}$ increase in the E2-treated women ranged from 162-738\% of their baseline values.

The progesterone and $\mathrm{LH}$ responses to endotoxin in an individual subject, a 68-yr-old woman who had undergone bilateral oophorectomy, are shown in Fig. 3A. She received the highest dose of endotoxin $(3 \mathrm{ng} / \mathrm{kg})$ and was the only subject noted to have a suppression of pulsatile LH release in the absence of E2. On E2 replacement, her LH increased from a baseline of $2.38 \mathrm{mIU} / \mathrm{mL}$ to a peak of $20.6 \mathrm{mIU} / \mathrm{mL}$, or a mean hourly rise of $738 \%$ at hour 7 , compared with her baseline (Fig. 3B).

\section{ACTH study}

After the Cortrosyn infusion, mean cortisol and progesterone concentrations increased significantly over time, in all subjects $(P<0.001)$. Cortisol and progesterone increased from a 2 -h baseline of $9.3 \pm 1.7 \mu \mathrm{g} / \mathrm{dL}$ and $0.6 \pm 0.2 \mathrm{ng} / \mathrm{mL}$ to a peak of $39.4 \pm 2.3 \mu \mathrm{g} / \mathrm{dL}$ and $1.9 \pm 0.2 \mathrm{ng} / \mathrm{mL}$, respectively, 3-4 h after the Cortrosyn injection (Fig. 4B). This rise in progesterone and cortisol was accompanied by a significant stimulation of LH release $(P<0.001)$, which was noted $2-3 \mathrm{~h}$ after the initial rise in progesterone. Mean hourly LH rose from a baseline of $13.3 \pm 3.0 \mathrm{mIU} / \mathrm{mL}$ to a peak of $44.1 \pm$ $11.7 \mathrm{mIU} / \mathrm{mL}$ (Fig. 4A). The peak mean hourly LH increase over baseline ranged from $158-770 \%$.

\section{Discussion}

Our data show, for the first time in humans, how a reproducible specific stressor has a markedly different effect on 
A

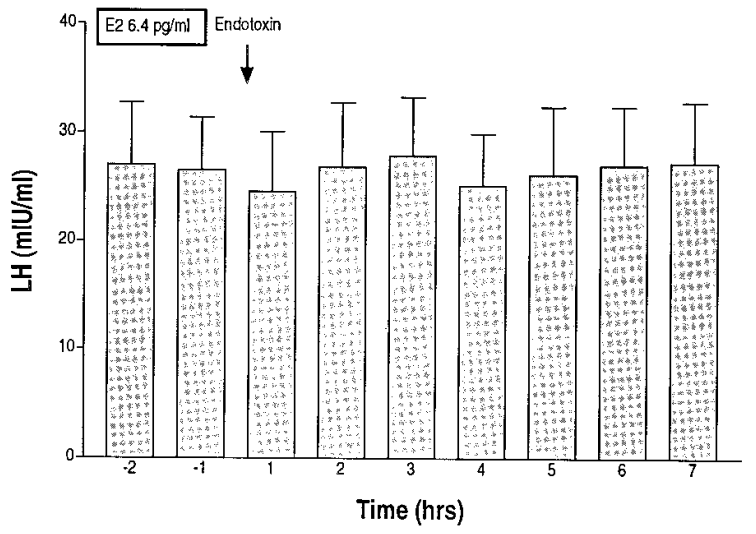

B

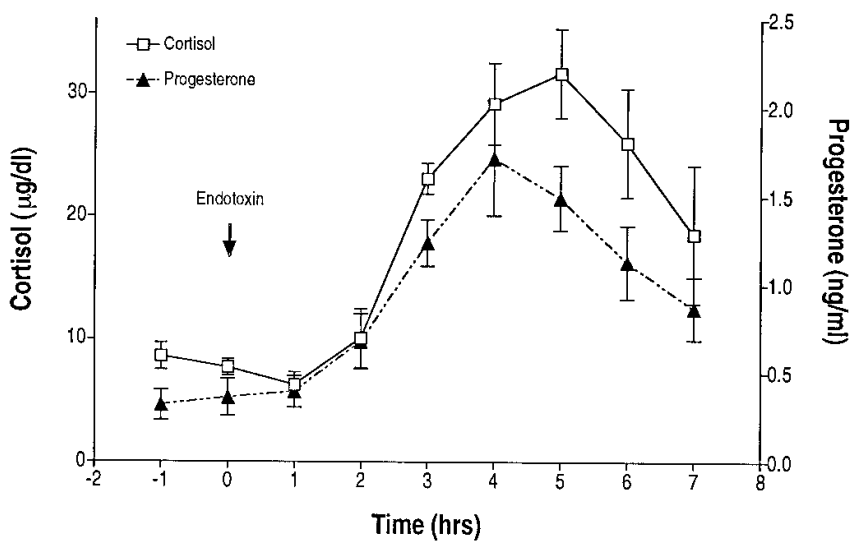

FiG. 1. Mean ( \pm SEM) LH (A), cortisol, and progesterone (B) responses to an endotoxin injection in five postmenopausal women without E2 replacement (mean E2 $=6.4 \pm 0.9 \mathrm{pg} / \mathrm{mL}$ ). Cortisol and progesterone levels rose significantly over time $(P<0.01)$, whereas LH plasma concentrations did not change significantly over time $(P=0.58)$.

the HPG axis in the presence or absence of estrogen. Endotoxin was chosen as the inflammatory stressor because of its stimulatory effects on the release of endogenous cytokines (IL-1, IL-6, tumor necrosis factor), which in turn activate the HPA axis and lead to the suppression of the HPG axis $(6,14-19)$.

Whereas, in the first part of our study, both cortisol and progesterone rose significantly after endotoxin injection in women with and without estrogen replacement, LH did not change significantly over time, in the unreplaced group as a whole. In contrast, most previous animal studies report a decrease in $\mathrm{LH}$ in response to endotoxin or IL- $1 \alpha$. Ovariectomized rhesus monkeys show a suppression in basal pulsatile LH secretion after endotoxin infusion, given in much higher amounts than have been administered to humans (20). A similar effect was seen in the monkey after IL-1 infusion (9) and in the male (14) and female $(15,17)$ rat. Our failure to see a decrease in LH after endotoxin in the estrogendeficient subjects is most likely related to the relatively low dose of endotoxin used in our subjects. In support of this is the observation that in the subject who received the highest dose of endotoxin, LH did indeed decrease.

The suppression of LH secretion by IL- $1 \alpha$ in the monkey
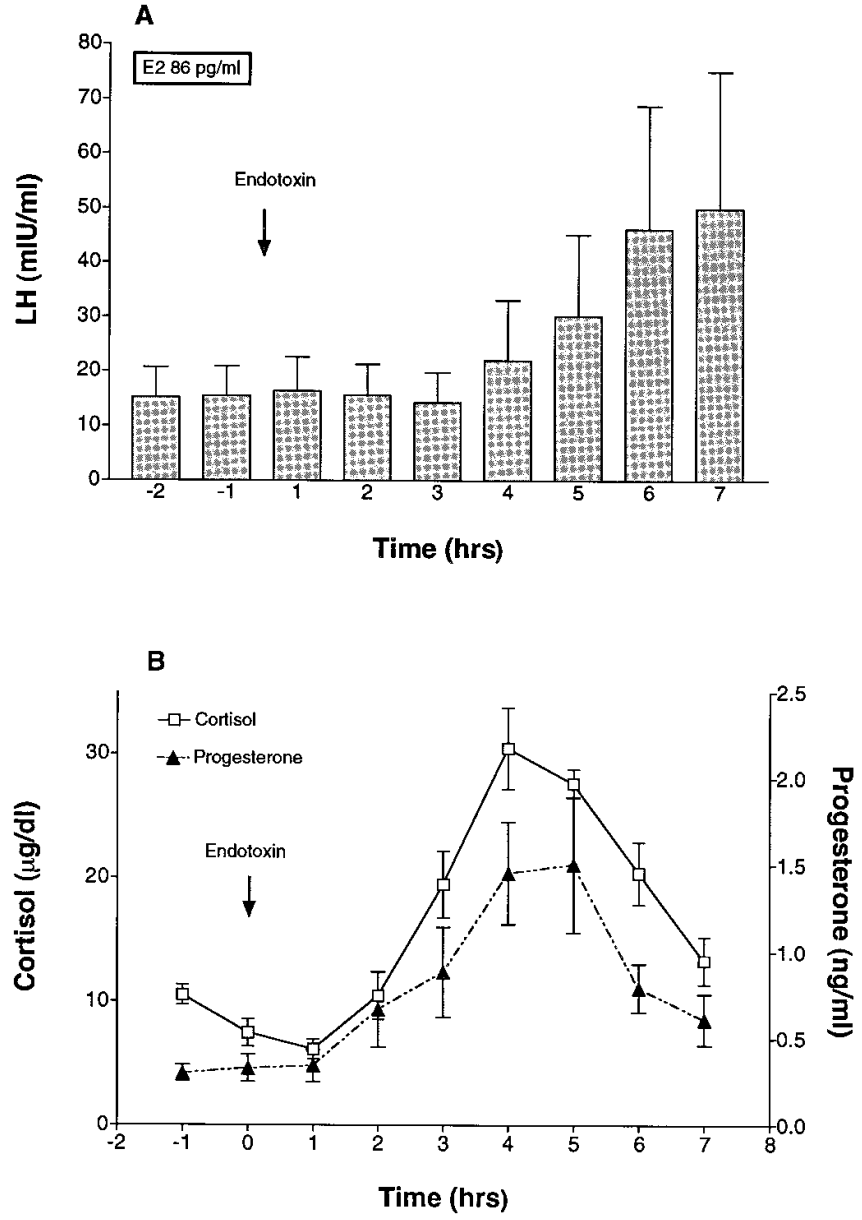

FIG. 2. Mean ( \pm SEM) LH (A), cortisol, and progesterone (B) responses to an endotoxin injection in five postmenopausal women with E2 replacement (mean E2 $=86 \pm 10 \mathrm{pg} / \mathrm{mL}$ ). Cortisol and progesterone levels rose significantly over time $(P<0.001)$. This was accompanied by a significant stimulation of $\mathrm{LH}$ release $(P=0.02)$.

can be blocked by a CRH antagonist, supporting a role for $\mathrm{CRH}$ in this process (9). Other forms of stress have also been shown to decrease LH in animals by a CRH mediated-mechanism (3). Although there are no direct data in humans, hypothalamic $\mathrm{CRH}$ levels are thought to be elevated in women with hypothalamic amenorrhea and in highly trained runners, because both groups have elevated basal cortisol levels and blunted cortisol responses to CRH $(8,21)$. Elevated CRH levels have been reported in the CSF of amenorrheic women with anorexia nervosa (22).

In contrast to the low estrogen state, endotoxin administration did lead to a significant stimulation of plasma LH levels in the same postmenopausal women after 1 month of E2 replacement. In animals, there is evidence that a critical E2 concentration may be necessary for stress-induced stimulation of the HPG axis to occur. In both E2-replaced ovariectomized monkeys (with plasma E2 concentrations characteristic of the late follicular phase of the menstrual cycle) and in intact monkeys during the midfollicular phase, ICV IL- $1 \alpha$ administration stimulated LH release $(12,13)$. However, no significant change in LH levels was observed when IL- $1 \alpha$ was administered to intact monkeys during the early follic- 

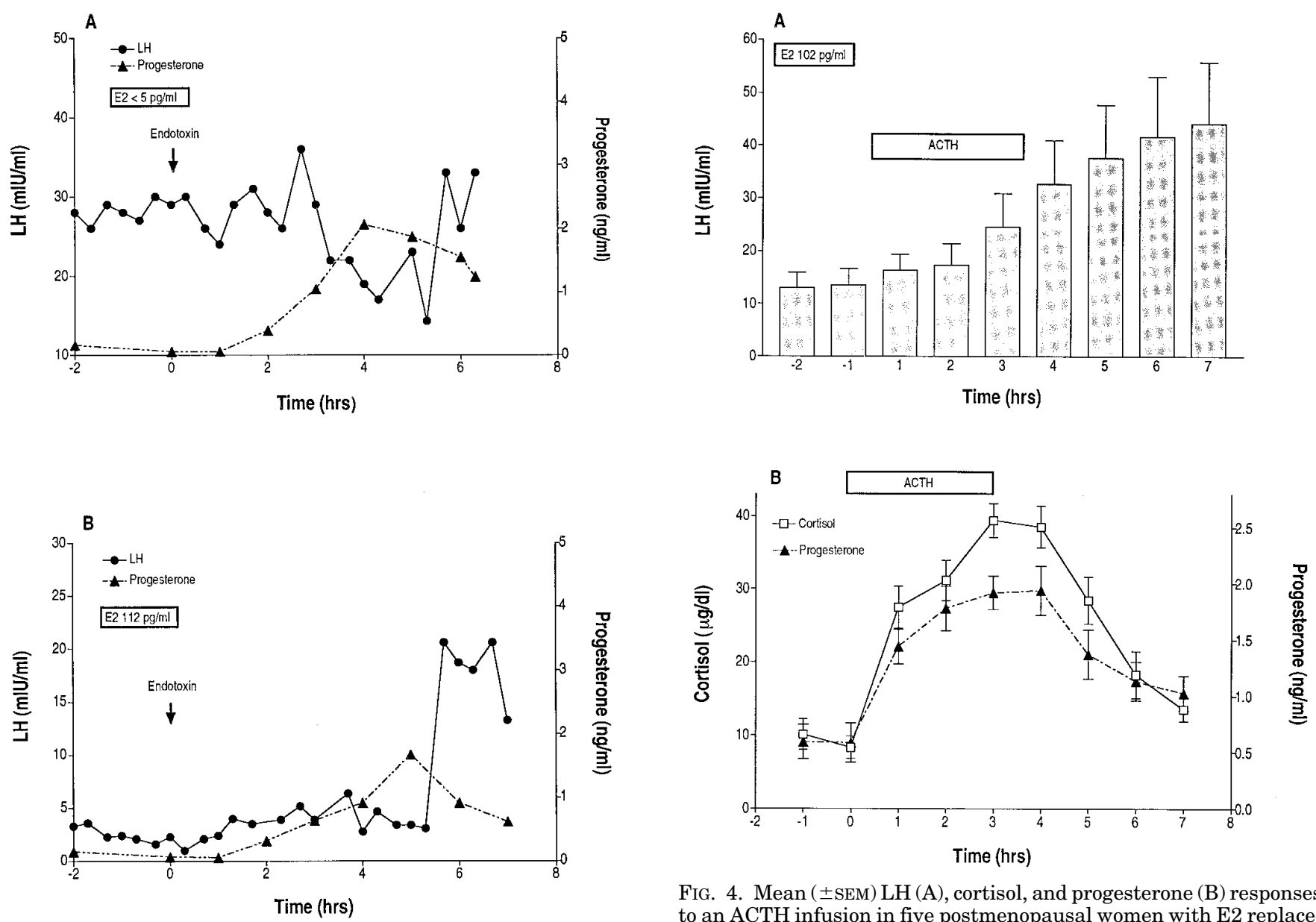

FIG. 3. Illustration of the effects of endotoxin on progesterone concentration and pulsatile $\mathrm{LH}$ release in an ovariectomized woman without (A, E2 $<5 \mathrm{pg} / \mathrm{mL}$ ) and with (B, E2 = $112 \mathrm{pg} / \mathrm{mL})$ E2 replacement.

ular phase (13). In addition, ICV injection of CRH into gonadectomized ewes, in the presence of exogenous E2, resulted in a significant increase in both LH pulse frequency and mean LH concentrations (23).

To determine whether the endotoxin-induced stimulation of LH release in the E2-treated subjects was primarily caused by adrenal stimulation, we performed a second study, in which we investigated the effects of direct adrenal stimulation by a Cortrosyn infusion in E2-replaced postmenopausal women. As in the first study, the rise in cortisol and progesterone in response to Cortrosyn infusion was accompanied by a significant LH increase. In both studies, the rise in progesterone preceded the LH rise by several hours, similar to what has been reported previously in animal studies. These findings are consistent with a synergistic role of progesterone in stimulating LH secretion. In monkeys, infusion of a CRH antagonist prevented both the increase in progesterone and the increase in LH seen after IL- $1 \alpha$ treatment. In addition, an increase in LH did not occur when the E2replaced animals were pretreated with RU486, a progesterone antagonist, although the increase in progesterone itself was not prevented (12). It is thus postulated that progester-

FIG. 4. Mean ( \pm SEM) LH (A), cortisol, and progesterone (B) responses to an ACTH infusion in five postmenopausal women with E2 replacement (mean E2 = $102 \pm 18 \mathrm{pg} / \mathrm{mL}$ ). Cortisol and progesterone levels rose significantly over time $(P<0.001)$. This was accompanied by a significant stimulation of LH release $(P<0.001)$.

one facilitates estrogen's positive feedback effects on LH secretion. There is evidence that progesterone can stimulate LH secretion by acting directly on the pituitary (24). Interestingly, in all of the above studies, the progesterone is most likely of adrenal origin, because the increase was observed in ovariectomized monkeys, as well as in several women in our study who were also ovariectomized. In the monkey and in our human studies, the plasma progesterone level did not exceed $2 \mathrm{ng} / \mathrm{mL}$. In contrast to primate studies, IL-1 administration to ovariectomized, E2-replaced rodents did not increase LH. This phenomenon has been attributed to the very high $(>50 \mathrm{ng} / \mathrm{mL})$ progesterone levels found in the rat after an inflammatory stimulus $(15,16)$. At high concentrations, progesterone is known to inhibit LH release.

There are a few clinical studies in humans that support our observation of a rise in LH after stress. When untrained eumenorrhoeic women were stressed by exercise during the midfollicular phase of the cycle, a small increase in maximal peak amplitude of plasma LH was observed (25). In another study, eumenorrheic athletes were compared with sedentary women with normal menstrual cycles. The athletes had higher mean serum LH levels, resulting primarily from an increase in LH pulse amplitude, although there was a de- 
crease in LH pulse frequency (26). When eumenorrheic runners were studied in the follicular phase of the cycle, an increase of LH was seen immediately after a race, but this effect was not seen when the same women were studied 12-24 $\mathrm{h}$ after a run (27).

The physiologic significance of an acute $\mathrm{LH}$ rise in the follicular phase of the cycle is not known. There are no data specifically related to the effects of a stress-induced premature increase of LH in the mid- to late follicular phase. Several reports, however, indicate that elevated LH concentrations at that stage of the menstrual cycle may have adverse effects on the maturing follicle and on the developing oocyte and may result in early pregnancy loss (28) or in reduction in the fertilization rate of mature oocytes in women undergoing in vitro fertilization (29). One of the major causes of decreased fertility of unstimulated cycles is the occurrence of premature LH surges $(30,31)$. A potential negative effect of poorly timed increase in LH may be premature luteinization. It could thus be speculated that stress in the follicular phase may cause subtle interference with the menstrual cycle and fertility without interrupting the cycle completely.

Even though we only studied the immediate effects of acute stress, data in the nonhuman primate suggest that the effects of a more prolonged exposure to stress might have similar effects and that these effects may last beyond one menstrual cycle. Monkeys who received 5 days of endotoxin in the follicular phase subsequently had prematurely elevated levels of LH and FSH and experienced a number of menstrual abnormalities. These abnormalities included a prolonged follicular phase and instances of decreased follicular function during the treatment cycle itself and signs of luteal deficiency in the form of decreased progesterone secretion in the menstrual cycles thereafter (32).

In summary, our data provide evidence that, in the presence of adequate estrogen levels, stress-induced activation of the HPA axis is associated with the stimulation of LH release. The increase in LH is most probably related to the increase in adrenal progesterone that accompanies the release of cortisol in response to stress. Our results provide a mechanism in the human by which an acute stress in the mid- to late follicular phase of the menstrual cycle might provoke a premature LH surge and thereby interfere with proper follicular maturation and ovulation.

\section{Acknowledgments}

The technical assistance of Alinda Barth, Irene Conwell, and Ritu S. Baral was greatly appreciated.

\section{References}

1. Christian JJ, Loyd JA, David DE. 1965 The role of endocrines in the self regulation of mammalian populations. Recent Prog Horm Res. 21:501-570.

2. Lachelin GCL, Yen SSC. 1978 Hypothalamic chronic anovulation. Am J Obstet Gynecol. 130:825-831.

3. Rivier C, Rivier J, Vale W. 1986 Stress-induced inhibition of reproductive function: role of endogenous corticotropic releasing factor. Science. 231:607-609.

4. Rivier C, Rivest S. 1991 Effects of stress on the activity of the hypothalamicpituitary gonadal axis: peripheral and central mechanisms. Biol Reprod. 45:523-532.

5. Ferin M. 1999 Stress and the reproductive cycle. J Clin Endocrinol Metab. 84:1768-1774.

6. Rivest S, Rivier C. 1995 The role of corticotropin-releasing factor and interleukin-1 in the regulation of neurons controlling reproductive functions. Endocr Rev. 16:177-199.
7. Petraglia F, Sutton S, Vale W, Plotsky P. 1987 Corticotropin-releasing factor decreases plasma luteinizing hormone levels in female rats by inhibiting gonadotropin-releasing hormone release into hypophysial-portal circulation. Endocrinology. 120:1083-1088.

8. Olster DH, Ferin M. 1987 Corticotropin-releasing hormone inhibits gonadotropin secretion in the ovariectomized rhesus monkey. J Clin Endocrinol Metab. 65:262-267.

9. Feng YJ, Shalts E, Xia L, et al. 1991 An inhibitory effect of interleukin- $1 \alpha$ on basal gonadotropin release in the ovariectomized rhesus monkey: reversal by a corticotropin-releasing factor antagonist. Endocrinology. 128:2077-2082.

10. Biller BM, Federoff HJ, Koenig JI, Klibanski A. 1990 Abnormal cortisol secretion and responses to corticotropin-releasing hormone in women with hypothalamic amenorrhea. J Clin Endocrinol Metab. 70:311-317.

11. Berga Sl, Mortola JF, Girton L, et al. 1989 Neuroendocrine aberrations in women with functional hypothalamic amenorrhea. J Clin Endocrinol Metab. 68:301-308.

12. Xia E, Xia L, Shanen D, Khabele D, Ferin M. 1994 Stimulatory effects of interleukin-induced activation of the hypothalamo-pituitary-adrenal axis on gonadotropin secretion in ovariectomized monkeys replaced with estradiol. Endocrinology. 135:2093-2098.

13. Xia E, Xia L, Thornell D, Ferin M. 1996 Interleukin 1 stimulates luteinizing hormone release during the midfollicular phase in the rhesus monkey: a novel way in which stress may influence the menstrual cycle. J Clin Endocrinol Metab. 81:2136-2141.

14. Rivier C, Vale W. 1989 In the rat, interleukin- $1 \alpha$ acts at the level of the brain and the gonads to interfere with gonadotropin and sex steroid secretion. Endocrinology. 124:2105-2109.

15. Rivier C, Vale W. 1990 Cytokines act within the brain to inhibit luteinizing hormone secretion and ovulation in the rat. Endocrinology. 127:849-856.

16. Rivest S, Lee S, Attardi B, Rivier C. 1993 The chronic intracerebroventricular infusion of interleukin- $1 \beta$ alters the activity of the hypothalamic-pituitarygonadal axis of cycling rats. I. Effect on LHRH and gonadotropin biosynthesis and secretion. Endocrinology. 133:2424-2430.

17. Kalra PS, Sahu A, Kalra SP. 1990 Interleukin-1 inhibits the ovarian steroidinduced luteinizing hormone surge and release of hypothalamic luteinizing hormone-releasing hormone in rats. Endocrinology. 126:2145-2152.

18. Battaglia DF, Beaver AB, Harris TG, Tanhehco E, Viguié C, Karsch FJ. 1999 Endotoxin disrupts the estradiol-induced luteinizing hormone surge: interference with estradiol signal reading, not surge release. Endocrinology. 140:2471-2479.

19. Ferin M. 1993 Neuropeptides, the stress response, and the hypothalamopituitary-gonadal axis in the female monkey. Ann NY Acad Sci. 697:106-116.

20. Xia E, Xia-Zhang L, Ferin M. 2000 Inhibitory effects of endotoxin on LH secretion in the ovariectomized monkey are prevented by naloxone but not by an interleukin-1 receptor antagonist. Neuroimmunomodulation. 7:6-15.

21. Luger A, Deuster PA, Kyle SB, et al. 1987 Acute hypothalamic-pituitaryadrenal responses to the stress of treadmill exercise. Physiologic adaptations to physical training. N Engl J Med. 316:1309-1315.

22. Kaye WH, Gwirtsman HE, George DT, et al. 1987 Elevated cerebrospinal fluid levels of immunoreactive corticotropin-releasing hormone in anorexia nervosa: relation to state of nutrition, adrenal function and intensity of depression J Clin Endocrinol Metab. 64:203-208.

23. Caraty A, Miller DW, Delaleu B, Martin GB. 1997 Stimulation of LH secretion in sheep by central administration of corticotrophin-releasing hormone. J Reprod Fertil. 111:249-257.

24. Couzinet B, Brailly S, Bouchard P, Schaison G. 1992 Progesterone stimulates luteinizing hormone secretion by acting directly on the pituitary. J Clin Endocrinol Metab. 74:374-378

25. Williams NI, McArthur JW, Turnbull BA, et al. 1994 Effects of follicular phase exercise on luteinizing hormone pulse characteristics in sedentary eumenorrhoeic women. Clin Endocrinol (Oxf). 41:787-794.

26. Loucks AB, Mortola JF, Girton L, Yen SSC. 1989 Alterations in the hypothalamic-pituitary-ovarian and the hypothalamic-pituitary-adrenal axes in athletic women. J Clin Endocrinol Metab. 68:402-411.

27. Baker ER, Mathur RS, Kirk RF, Landgrebe SC, Moody LO, Williamson HO. 1982 Plasma gonadotropins, prolactin, and steroid hormone concentrations in female runners immediately after a long-distance run. Fertil Steril. 38:38-41.

28. Watson H, Kiddy DS, Hamilton-Farley D, et al. 1993 Hypersecretion of luteinizing hormone and ovarian steroids in women with recurrent early miscarriage. Hum Reprod. 8:829-833.

29. Stanger JD, Yovich JL. 1985 Reduced in vitro fertilization of human oocytes from patients with raised basal luteinizing hormone levels during the follicular phase. Br J Obstet Gynaecol. 92:385-393.

30. Paulson RJ, Sauer MV, Francis MM, Macaso TM, Lobo RA. 1990 In vitro fertilization in unstimulated cycles: a clinical trial using hCG for timing of follicle aspiration. Obstet Gynecol. 76:788-791.

31. Paulson RJ, Sauer MV, Francis MM, Macaso TM, Lobo RA. 1992 In vitro fertilization in unstimulated cycles: the University of Southern California experience. Fertil Steril. 57:290-293.

32. Xiao E, Xia-Zhang L, Barth A, Zhu J, Ferin M. 1998 Stress and the menstrual cycle: relevance of cycle quality in the short-and long-term response to a 5-day endotoxin challenge during the follicular phase in the rhesus monkey. J Clin Endocrinol Metab. 83:2454-2460. 